P ISSN : 2503 - 1708

E ISSN : 2722 - 7340

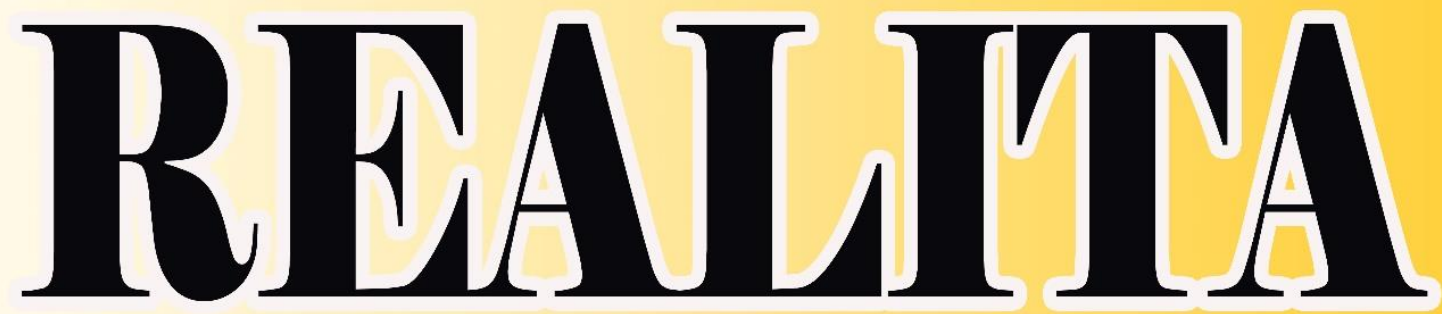

Jurnal Bimbingan dan Konseling

\begin{tabular}{|c|c|c|c|c|c|}
\hline JURNAL & VOLUME & NOMOR & EDISI & HALAMAN & P ISSN : 2503 - 1708 \\
REALITA & 6 & 2 & Oktober 2021 & $1326-1430$ & E ISSN : 2722 - 7340 \\
\hline
\end{tabular}

Diterbitkan oleh:

PROGRAM STUDI BIMBINGAN DAN KONSELING FAKULTAS ILMU PENDIDIKAN DAN PSIKOLOGI UNIVERSITAS PENDIDIKAN MANDALIKA 


\section{REALITA \\ BIMBINGAN DAN KONSELING \\ Jurnal Penelitian dan Pengembangan Pendidikan}

\section{DEWAN REDAKASI \\ Pelindung : Rektor Universitas Pendidikan Mandalika \\ : Dekan FIPP Universitas Pendidikan Mandalika \\ Penanggung \\ Jawab \\ : Kaprodi BK FIPP Universitas Pendidikan Mandalika \\ Editor}

Hariadi Ahmad, M.Pd

Universitas Pendidikan Mandalika

Associate Editor

Mustakim, M.Pd

Universitas Pendidikan Mandalika

Mujiburrahman, M.Pd

Universitas Pendidikan Mandalika

Ahmad Muzanni, M.Pd

Universitas Pendidikan Mandalika

M. Chaerul Anam, M.Pd

Universitas Pendidikan Mandalika

\section{Editorial Board}

Prof. Drs. Kusno, DEA., Ph.D

Universitas Negeri Jember Jawa Timur

Drs. Wayan Tamba, M.Pd

Farida Herna Astuti, M.Pd

Ichwanul Mustakim, M.Pd

Reza Zulaifi, M.Pd

Jessica Festi Maharani, M.Pd

Universitas Pendidikan Mandalika

Universitas Pendidikan Mandalika

Universitas Pendidikan Mandalika

Universitas Pendidikan Mandalika

Universitas Pendidikan Mandalika

\section{Reviwer}

Dr. I Made Sonny Gunawan, S.Pd., M.Pd

Universitas Pendidikan Mandalika

Dr. A. Hari Witono, M.Pd

Universitas Mataram NTB

Prof. Dr. Wayan Maba

Universitas Mahasaraswati Bali

Dr. Gunawan, M.Pd

Universitas Mataram NTB

Dr. Haromain, S.Pd., M.Pd.

Universitas Pendidikan Mandalika

Dr. Hadi Gunawan Sakti, M.Pd

Wiryo Nuryono, M.Pd

Hasrul, S.PdI., M.Pd

Dita Kurnia Sari, M.Pd

Dr. Roro Umy Badriyah. M.Pd., Kons

Universitas Pendidikan Mandalika

Universitas Negeri Surabaya Jawa Timur

STKIP Kie Raha Ternate Maluku Utara

UIN Sunan Ampel Surabaya Jawa Timur

Universitas PGRI Maha Dewa Bali

Ari Khusumadewi, M.Pd

Universitas Negeri Surabaya Jawa Timur 
M. Najamuddin, M.Pd

M. Samsul Hadi, M.Pd

Lalu Jaswandi, M.Pd

Eneng Garnika, M.Pd

Aluh Hartati, M.Pd

Drs. I Made Gunawan, M.Pd

Nuraeni, S.Pd., M.Si

Baiq Sarlita Kartiani, M.Pd

M. Zainuddin, M.Pd

Ahmad Zainul Irfan, M.Pd

Dra. Ni Ketut Alit Suarti, M.Pd

Asep Sahrudin, S.Pd., M.Pd

Suciati Rahayu Widyastuti, S.Pd., M.Pd

Rahmawati M, S.Pd., M.Pd

Ginanjar Nugraheningsih, S.Pd. Jas., M.Or

Dewi Ariani, S.Pd., M.Pd

St. Muriati, S.Pd., M.Pd

Uli Agustina Gultom, S.Pd., M.Pd

Indra Zultiar, S.Pd., M.Pd.
Universitas Pendidikan Mandalika

Universitas Pendidikan Mandalika

Universitas Pendidikan Mandalika

Universitas Pendidikan Mandalika

Universitas Pendidikan Mandalika

Universitas Pendidikan Mandalika

Universitas Pendidikan Mandalika

Universitas Pendidikan Mandalika

Universitas Pendidikan Mandalika

Universitas Pendidikan Mandalika

Universitas Pendidikan Mandalika

Univ. Mathla'ul Anwar Banten

Univ. Nahdlatul Ulama Cirebon

Universitas Muhammadiyah Kendari Sulawesi Tenggara

Universitas Mercu Buana Yogyakarta

Universitas Mahaputra Muhammad Yamin Solok Sumatera Barat

Universitas Bosowa Makassar Sulawesi Selatan

Universitas Borneo Tarakan Kalimantan Utara

Universitas Muhammadiyah Sukabumi Jawa Barat

\section{Alamat Redaksi:}

Redaksi Jurnal Realita Bimbingan dan Konseling (JRbk)

Program Studi Bimbingan dan Konseling

Fakultas Ilmu Pendidikan dan Psikologi Universitas Pendidikan Mandalika

Gedung Dwitiya, Lt. 3 Jalan Pemuda No. 59 A Mataram Telp. (0370) 638991

Email : realita@undikma.ac.id

Web : e-journal.undikma.ac.id

Jurnal Realita Bimbingan dan Konseling menerima naskah tulisan penulis yang original (belum pernah diterbitkan sebelumnya) dalam bentuk soft file, office word document (Email) atau Submission lansung di akun yang diterbitkan setiap bulan April dan Oktober setiap tahun.

Diterbitkan Oleh: Program Studi Bimbingan dan Konseling Fakultas Ilmu Pendidikan dan Psikologi Universitas Pendidikan Mandalika. 


\section{DAFTAR ISI}

Halaman

\section{Nuraeni dan Mastari}

Pengaruh Konseling Kelompok Terhadap Self Esteem Siswa Kelas XI di SMK Negeri 2 Kuripan

\section{Aprilia Yolanda, Ni Ketut Alit Suarti dan Ahmad Muzanni}

Pengaruh Body Shaming Terhadap Kepercayaan Diri Siswa SMA Negeri

1 Batulayar

$1342-1353$

\section{Hariadi Ahmad}

Hubungan Kestabilan Emosi dengan Kontrol Diri Siswa Sekolah Menegah Pertama

\section{Aluh Hartati}

Pengaruh Teknik Modeling Untuk Meningkatkan Empati Siswa

\section{Mustakim}

Pengaruh Teknik Cerita Terhadap Sikap Kemandirian Anak Pada Usia 5-6 Tahun

\section{Farida Herna Astuti dan Ichwanul Mustakim}

Keefektifan Bimbingan Kelompok dengan Teknik Role Playing untuk Meningkatkan Motivasi Belajar

\section{Mujiburrahman dan Soba Al-Qadri}

Hubungan Antara Kemampuan Kontrol Diri Dengan Penyusaian Diri Pada Siswa Kelas XI SMA Negeri 1 Taliwang

\section{Wiwiek Zainar Sri Utami}

Pengaruh Konseling Individu Terhadap Potensi Diri Anak Tunarungu di Sekolah Inklusi

\section{Baiq Nur'aini Cahya Khairani dan Ni Made Sulastri}

Pengaruh Layanan Konseling Humanistik Terhadap Perilaku Agresif pada Siswa Kelas XI IPS-4 di SMA Negeri 7 Mataram

\section{Najamudin}

Pengaruh Teknik Biblioterapi Terhadap Sikap Kemandirian Belajar Pada Siswa VIII SMP Negeri 5 Lembar

\section{Khaerul Huda}

Meningkatkan Pengetahuan dan Pemahaman Perilaku Hidup Bersih dan Sehat dimasa Covid 19 Melalui Metode Demontrasi pada Kelompok B di TK Negeri 01 Wanasaba 


\title{
HUBUNGAN ANTARA KEMAMPUAN KONTROL DIRI DENGAN PENYESUAIAN DIRI PADA SISWA KELAS XI SMA NEGERI 1 TALIWANG
}

\author{
Oleh: \\ Mujiburrahman dan Soba Al-Qadri \\ Program Studi Bimbingan dan Konseling Fakultas Ilmu Pendidikan dan Psikologi \\ Universitas Pendidikan dan Psikologi Universitas Pendidikan Manadlika \\ Mataram NTB Indonesia \\ Email: mujiburrahman@ikipmataram.ac.id; sobaalqadri123@gmail.com
}

\begin{abstract}
Abstrak. Kontrol diri adalah kemampuan untuk mengontrol diri dan mengelolah perilaku sesuai dengan situasi dan kondisi untuk menampilkan perilaku, menarik perhatian, mengubah perilaku yang menyenangkan orang lain. Penyesuian diri adalah mengubah perilaku individu agar terjadi hubungan yang lebih sesuai dengan kondisi lingkungannya. Rumusan masalah penelitian ini adalah Apakah Ada Hubungan Antara Kemampuan Kontrol Diri Dengan Penyesuian Diri Pada Siswa Kelas XI SMA Negeri 1 Taliwang Kabupaten Sumbawa Barat Tahun Pelajaran 2020/2021. Tujuan penelitian ini adalah ingin Mengetahui Hubungan Antara Kontrol Diri Dengan Penyesuian Diri Pada Siswa Kelas XI SMA Negeri 1 Taliwang Kabupaten Sumbawa Barat Tahun Pelajaran 2020/2021. Teknik pengumpulan data mengunakan Teknik Studi Populasi. Populasi dalam penelitian ini adalah siswa SMA Negeri 1 Taliwang Kabupaten Sumbawa Barat Tahun Pelajaran 2020/2021. Dengan jumlah siswa 107 orang. Metode pengumpulan data yang digunakan adalah metode angket, dan angket merupakan metode pokok sedangkan dokumentasi adalah metode pendukung. Untuk menganalisis data menggunakan rumus korelasi. Berdasarkan hasil perhitungan nilai $r_{x y}$ yang diperoleh 10,059, sedangkan nilai $r_{x y}$ tabel 0,176, 5\% dan $\mathrm{N}=107$ maka dapat diperoleh 10,059>0,176, kenyataan ini menunjukan bahwa nilai $r_{x y}$ yang diperoleh dalam penelitian ini adalah lebih besar dari pada nilai $r_{x y}$ tabel, maka hipotesis nol (Ho) ditolak dan hipotesi alternatif (Ha) diterima. Jadi kesimpulan analisis penelitian adalah: Ada Hubungan Antara Kontrol Diri Dengan Penyesuian Diri Pada Siswa Kelas XI SMA Negeri 1 Taliwang Kabupaten Sumbawa Barat Tahun Pelajaran 2020/2021. Dapat sipulkan Bahwa hasil penelitian ini signifikan.
\end{abstract}

\section{Kata Kunci: Kontrol Diri dan Penyesuian Diri}

\section{PENDAHULUAN}

Manusia dalam kehidupan keseharianya tidak akan perna bebas dari berbagai perasaan yang tidak menyenangkan. Seorang dikatakan tidak mampu menyesuikan diri apabila kesedihan, kekecewaan, atau keputusan itu berkembang dan mempengaruhi fungsi fisiologis dan psikologisnya. Individu menjadi tidak mampu mengatasi tekanantekanan yang muncul dengan jalan yang baik. Sebaliknya, seorang dikatakan mempunyai penyusuian diri yang berhasil apabila ia mencapai kepuasaan dalam usahanya memenuhi kebutuhan, mengatasi ketengangan, bebas dari berbagai psikologis, frustasi, dan konflik
(Adelbert, 2014). Setiap orang membutuhkan pengandalian diri, begitu juga para remaja. Namun kebanyakan dari mereka belum mampu mengontrol dirinya, karena dia belum mempunyai pengalaman yang memadai untuk dirinya. Dia akan sangat peka karena pertmbuhan fisik dan seksual tersebut, terjadi kegoncangan dan kebimbangan dalam dirinya terutama dalam pergaulan terhadap lawan jenis (Panuju \& Umami, 1999).

$\begin{array}{lcr}\text { Peserta } & \text { didik } & \text { secara } \\ \text { alami dibekali } & \text { kemampuan } & \text { untuk } \\ \text { menolong dirinya } & \text { sendiri } & \text { dengan } \\ \text { cara menyesuaikan } & \text { diri } & \text { dengan } \\ \text { keadaan lingkungan, } & \text { agar dapat } & \text { bertahan }\end{array}$


dalam keadaan yang berbeda dari sebelumnya. Namun pada kenyataannya, banyak peserta didik yang gagal dalam penyesuaian diri karena belum tentu tahu apa yang dinamakan dengan proses penyesuaian diri, selain itu peserta didik tidak memiliki konsep penyesuaian diri dan tidak melakukan penyesuaian diri dengan baik. Hal ini sangat berpengaruh terhadap kehidupan peserta didik dalam menghadapi segala tantangan dan perubahan-perubahan yang akan terjadi nanti (Hariadi A dan Aluh $\mathrm{H}$. 2016). Pentingnya penyesuaian diri pada peserta didik sangat diperlukan karena terdapat banyak peserta didik yang tidak mampu mencapai kebahagiaan dalam hidupnya, karena ketidakmampuan dalam menyesuaikan diri, baik dengan kehidupan keluarga, sekolah, dan dalam masyarakat pada umumnya.Tidak jarang pula ditemui bahwa peserta didik mengalami stres dan depresi disebabkan oleh kegagalan mereka untuk melakukan penyesuaian diri dengan kondisi penuh tekanan (Fatimah, 2010).

Setiap individu memiliki suatu mekanisme yang dapat membantu mengatur dan mengarahkan perilaku. Mekanisme yang dimaksud diatas adalah kontrol diri. Kontrol diri pada satu individu dengan individu yang lain tidaklah sama. Ada individu yang memiliki kontrol diri yang tinggi dan ada individu yang memiliki kontrol diri yang rendah. Peserta didik yang memiliki kontrol diri yang tinggi, kemungkinan akan mampu mengontrol dan mengarahkan perilakunya. Peserta didik tersebut pada umumnya masih dapat mengontrol dorongan-dorongan yang ada dalam dirinya. Sedangkan peserta didik yang memiliki kontrol diri rendah, kemungkinan cenderung tidak mampu melepaskan diri dari dorongan-dorongan untuk melakukan hal-hal yang negative (Hariadi A, Aluh H, dan Nuraeni. 2018)
Penyesuaian diri merupakan suatu proses alamiah dan dinamis yang bertujuan mengubah prilaku individu agar terjadi hubungan yang lebih sesuai dengan kondisi lingkunganya. (Fatimah, 2010). Sedangkan menurut Risnawita \& Ghufron (2012) penyesuian diri adalah salah satu aspek penting dalam usaha manusia untuk menguasai perasaan yang tidak menyenangkan atau tekanan akibat dorongan kebutuhan, usaha memelihara keseimbangan antara memenuhi kebutuhan dan tuntutan lingkungnya, dan usaha menyelaraskan hubungan individu dengan realitas.

Berdasarkan observasi awal pada pra penelitian ini, selama pelaksanaan PLP dan KKN ditemukan beberapa hal yang menjadi masalah yaitu siswa di SMA Negeri 1 Taliwang belum mampu menyesuikan dirinya dalam mengahadapi tuntutan-tuntutan, baik dari dalam diri maupun dari lingkungan sehingga tidak terdapat keseimbangan antara pemenuhan kebutuhan dengan tuntutan lingkungan. Pemenuhan kebutuhan dan lingkungan merupakan satu kesatuan yang tidak bisa dipisahkan antara satu dengan yang lain seperti salah satu contohnya fasilitas internet yang ada. Selain fasilitas yang ada permasalahan sering muncul ialah permasalahan individu yang di antaranya siswa yang memiliki harga diri rendah, perkelahian antar siswa, siswa yang memiliki masalah bersosialisasi dan sulit mengendalikan emosi sedangkan untuk masalah penyesuaian diri adalah kurangnya siswa bergaul dengan teman, kurang melakukan organisasi disekolah, kurangnya belajar kelompok dengan teman. Bertitik tolak dari uraian di atas, maka peneliti tertarik untuk melakukan penelitian tentang: Hubungan Antara Kontrol Diri dengan Penyesuian Diri Pada Siswa Kelas XI SMA Negeri 1 Taliwang Kabupaten Sumbawa Barat Tahun Pelajaran 2020/2021. 


\section{TINJAUAN PUSTAKA}

Kontrol diri merupakan kecakapan individu dalam kepekaan membaca situasi diri dan lingkungan serta kemampuan untuk mengontrol dan mengelolah faktor-faktor prilaku sesuai dengan situasi dan kondisi untuk menampilkan diri dalam melakukan sosialisasi kemampuan untuk mengendalikan prilaku, kencendrung menarik perhatian, keinginan mengubah prilaku agar sesuai untuk orang lain, menyenangkan orang lain, selalu konfrom dengan oranglain, dan menutupi perasaannya (Risnawita \& Ghufron, 2012). Calhoun \& Acocella (1990) mendefinisikan kontrol diri (self control) sebagai pengaturan proses-proses fisik, psikologis, dan prilaku seseorang, dengan dengan kata lain serangkaian proses yang membentuk dirinya sendiri. Mendifinisikan kontrol diri sebagai kemampuan untuk menyususun, membimbing, mengatur dan mengarahkan bentuk prilaku yang dapat membawa individu kearah konsekensi positif. Selain itu kontrol diri mengambarkan keputusan individu yang melalui pertimbangan kognitif untuk menyatukan prilaku yang telah disusun untuk meningkatkan hasil dan tujuan tertentu.

Menurut Gottfredson \& Hirschi (1990) kontrol diri atau pengendalian diri yang rendah, memliki karakteristik yang stabil yang meningkatkan seseorang untuk melakukan tindakan-tindakan pidana atau tindakan yang menyimpang lainnya dalam kehidupan bersosial, dengan demikian dibutuhkan penyesuaian diri individu dengan karakteristik teman yang berbeda. Menurut Goleman (2005) kontrol diri adalah keterampilan untuk mengendalikan diri dari api-api emosi yang terlihat mencolok. Tanda-tandanya meliputi ketegasan saat menghadapi stres atau mengahadapi seseorang yang bersikap bermusuhan tanpa membalas dengan sikap atau perilaku serupa.

Ketika berinteraksi dengan orang lain, seseorang akan menampilkan perilaku yang dianggap paling tepat bagi dirinya, yaitu prilaku yang tepat menyelamatkan interaksinya dari akibat negative yang disebabkan karena respons yang dilakukannya. Kontrol diri diperlukan guna membantu individu dalam mengatasi berbagai hal merupakan yang mungkin yang terjadi berasal dari luar. Skinner menyatakan bahwa kontrol diri merupakan tindakan diri dalam mengontrol variable-variabel luar yang akan menentukan tingkah laku. Dan tingkah laku dapat dikontrol melalui berbagai cara yaitu menghindari, penjemuhan, stimuli yang tidak disukai, dan mempertkuat diri (Alwisol, 2009).

Berdasarka uraian diatas, maka disimpulkan bahwa control diri merupakan suatu pengandalian tingka laku seorang yang cenderung bertindak positif dalam berfikir. Maksud dari pengandalian tingka laku disini ialah melakukan berbagai pertimbangan terlebih dahulu sebelum memutuskan untuk bertindak agar sesuai atau nyaman dengan orang lain. Kontrol diri merupakan kecakapan individu dalam kepekaan membaca situasi diri dan lingkungan serta kemampuan untuk mengontrol agar dapat berprilaku sesuai dengan keadaan lingkungan. Adapun Indikator yang digunakan yaitu: 1). Kemampuan mengontrol perilaku, 2). Kemampuan mengontrol stimulus, 3). Kemampaun mengantisipasi suatu peristiwa atau kejadian, 4). Kemampuan menafsirkan peristiwa, 5). Kemampuan untuk mengambil keputusan

Penyesuaian diri merupakan suatu proses alamiah dan dinamis yang bertujuan mengubah prilaku individu agar terjadi hubungan yang lebih sesuai dengan kondisi lingkunganya (Fatimah, 2010). Sedangkan menurut Desmita 
(2014) penyesuaian diri merupakan suatu kontruks psikologi yang luas dan kompleks, serta melibatkan semua reaksi individu terhadap tuntutan baik dari lingkungan luar maupun dari dalam individu itu sendiri. Begitupun Sunarto (2008) menyatakan penyesuaian diri adalah proses bagaimana individu mencapai keseimbangan diri dalam memenuhi kebutuhan sesuai dengan lingkungan, yaitu; percaya diri, tidak ragu, tekad dan semangat, ketegasan dalam bertindak, ketabahan dalam menghadapi masalah/konflik, kematangan emosional/kontrol emosi, dan realistis/obyektif. Berdasarkan pengertin di atas dapat disimpulkan bahwa penyesuain diri adalah kemampuan individu dalam menghadapi tuntutan-tuntutan, baik dari dalam diri maupun dari lingkungan sehingga terdapat keseimbangan antara pemenuhan kebutuhan dengan tuntutan lingkungan. Kemudian, tercipta keselarasan antara individu dengan realitas.

Faktor-faktor yang mempengaruhi perkembangan kepribadian sebagai berikubeberapa pendapat ahli tersebut dapat penulis simpulkan bahwa, (a) kondisi fisik; (b) perkembangan dan kemasakan unsur- unsur perkembangan; (c) unsur penentu psikologik; (d) kondisi lingkungan; dan (e) unsur kebudayaan. Secara garis besar faktor-faktor yang mempengaruhi penyesuaian diri dibedakan menjadi dua.Pertama, faktor internal yaitu, faktor yang berasal dari dalam diri individu yang meliputi kondisi jasmani, psikologis, kebutuhan, kematangan intelektual, emosional, mental, dan motivasi.Kedua faktor eksternal yang berasal dari lingkungan yang meliputi lingkungan rumah, keluarga, sekolah, dan masyarakat (Risnawita \& Ghufron, 2012). Penyesuaian diri merupakan suatu proses alamiah dan dinamis yang bertujuan mengubah prilaku individu agar terjadi hubungan yang lebih sesuai dengan kondisi lingkunganya. Adapun indikator yang digunakan yaitu: 1). Percaya diri, 2) Tidak ragu, 3). Tekad dan semangat, 4). Ketegasan dalam bertindak, 5). Ketabahan dalam menghadapi masalah, 6). Kematangan emosional/control emsosi, 7). Realistis atau obyektif.

\section{METODE PENELITIAN}

Dalam penelitian ini terdapat dua variabel yakni variabel $\mathrm{X}$ disebut variabel bebas (independen) adalah Kontrol Diri, dan variabel Y disebut variabel terikat (dependen) adalah Penyesuian Diri siswa. Penelitian ini menggambarkan secara sistematis, aktual, akurat mengenai fakta yang akan diselediki tentang Hubungan Antara Kontrol Diri Dengan Penyesuian Diri pada siswa SMA Negeri 1 Taliwang Kabupaten Sumbawa Barat Tahun Pembelajaran 2020/2021. Populasi dan sampel dalam penelitian ini adalah populasi dalam penelitian ini adalah siswa kelas XI di SMA Negeri 1 Taliwang Kabupaten Sumbawa Barat Tahun Pembelajaran 2020/2021 dengan jumlah siswa 107 orang dengan teknik menggunakan studi populasi, dimana studi populasi adalah keseluruhan objek yang akan diteliti yang ada di semua wilayah penelitian. Instrumen penelitian menggunakan metode angket, observasi dan dokumentasi. Instrumen penelitian yang digunakan berupa angket dan metode pengumpulan data berupa observasi, wawancara dan dokumentasi. Teknik analisis data menggunakan rumus Korelasi Product Moment

\section{HASIL DAN PEMBAHASAN}

Berdasarkan hasil analisis kolerasi product moment bahwa nilai rxy lebih besar dari nilai r-tabel, maka penelitian ini dikatakan "signifikan". Hasil penelitian tersebut menyatakan bahwa 
kontrol diri merupakan kemampuan untuk mengatur, membimbing dan mengarahkan prilaku yang dapaat dikembangkan dan digunakan indiidu dalam menghadapi kondisi yang terdapat di lingkungan sekitarnya. Oleh (Risnawita \& Ghufron, 2012). Karena itu kontrol diri dapat diartikan sebagai pengandalian tingkah laku,selagi mendidik dapat mempertimbangkan terlebih dahulu sebelum memutuskan sesuatu untuk bertindak.

Penyesuaian diri yang dialami siswa tentu saja beragam dan berbeda satu sama lain. Karena dalam kenyataan, tidak selamanya individu akan berhasil dalam melakukan penyesuaian diri. Hal itu disebabkan adanya rintangan atau hambatan tertentu yang menyebabkan ia tidak mampu melakukan penyesuaian diri secara optimal. Rintangan-rintangan itu dapat bersumber dari dalam dirinya (keterbatasan) atau mungkin dari luar dirinya. Dalam hubungannya dengan rintangan-rintangan tersebut, ada individu-individu yang mampu melakukan penyesuaian diri secara positif, tetapi ada pula yang melakukan penyesuaian diri secara negative atau salah. Meningkatkan penyesuaian diri remaja sangatlah penting dalam upaya menjaga tumbuh kembangnya. Membantu remaja dalam meningkatkan kemampuan penyesuaian dirinya secara tidak langsung dapat meningkatkan control dirinya.

Kontrol diri dalam hal ini merupakan suatu kemampuan untuk menyusun, membimbing, mengatur, dan mengarahkan bentuk prilaku yang dapat membawa individu kerah konsekuensi positif. Kontrol juga mengambarkan keputusan individu yang melalui pertimbangan kognitif untuk menyatukan prilaku yang telah disusun untuk meningkatkan hasil dan tujuan tertentu seperti yang diinginkan (Risnawita \& Ghufron, 2012). Jadi penyesuaian diri sangat berhubungan dengan Kontrol diri, hal ini dapat dilihat dari cara siswa tersebut bergaul dengan remaja dan teman sebayanya. Maka hasil sementara menurut pengamatan jika penyesuaian diri baik maka control diri siswa akan lebih baik, begitupun sebaliknya jika penyesuaian diri kurang baik maka kontrol diri siswa kurang baik.

Kontrol diri merupakan kecakapan individu dalam kepekaan membaca situasi diri dan lingkungan serta kemampuan untuk mengentrol dan mengelolah faktor-faktor prilaku sesuai dengan situasi dan kondisi untuk menampilkan diri dalam melakukan sosialisasi kemampuan untuk mengendalaikan prilaku, kencendrungan menarik perhatian, keinginan mengubah prilaku agar sesuai untuk orang lain, menyenangkan orang lain, selalu konfrom dengan orng lain, dan menutupi persaannya. Dan penyesuaian diri merupakan suatu proses dinamik terus menerus yang bertujuan untuk mengubah kelakuan guna mendapatkan hubungan lebih serasi antara diri dan lingkungan serta hubungan interaksi yang kontinu dengan diri sendiri maupun orang lain, dan dengan dunia. Melalui kedua variable tersebut ingin diperoleh data tentang hubungan kontrol diri dengan penyesuaian diri pada siswa.

$$
\text { Setiap siswa memiliki }
$$

kepribadian yang berbeda - beda, perbedaan itu karena sifat unik yang dimiliki masing-masing individu. Maka penyesuaian diri individu akan mengarah ke arah well adjustment karena didalam bergaul siswa dapat menciptakan situasi pergaulan yang harmonis hal tersebut dilihat dari rasa tanggung jawab, ramah tamah, suka menolong kepada yang membutuhkan, tidak membedakan teman yang miskin dan yang kaya, menghormati orang yang lebih dewasa dan teman, memahami perasaan teman. Sehingga diperoleh kesimpulan bahwa di 
dalam proses belajar mengajar yang dilaksanakan di sekolah mengacu pada intelegensi siswa dimana jika siswa tersebut mempunyai intelegensi tinggi, kemungkinan siswa bisa menyesuaikan dirinya. Intelegensi dengan penyesuain diri saling beruhubangan dimana keduanya itu harus seimbang agar siswa dapat mencapai kehidupannya sesuai apa yang diharapkannya.

Adapun menurut penjelasan Tu'u, (2004) kontrol diri yang dimiliki siswa berhubungan erat dengan penyesuaian diri. Siswa yang memiliki penyesuaian diri yang tinggi akan mampuh menginterprestasikan setiap stimulus yang diberikan, mempertimbangkannya dan memilih tindakan yang akan di lakukan dengan meminimalkan konsekuensi atau dampak yang tidak di inginkan. Sebaliknya, dengan siswa yang memiliki kontrol diri yang rendah, mereka akan kesulitan dalam mengarahkan dan mengatur prilaku sehinggga mereka akan cendrung menundah tuntan tugas sebagai siswa, dan mengalihkannya kepada kegiatan yang lebih menyenangkan.

Kenyataan

dilapangan

menunjukkan bahwa skor angket tentang kontrol diri sejumlah 8532, dan penyesuaian diri berjumlah 8449 . Kemudian setelah dihitung menggunakan rumus product moment hasil pengujian hipotesis menunjukkan bahwa diprtoleh nilai sebesar 10,059, kemudian dibandingkan dengan nilai rxy dalam tabel dari 107 siswa pda taraf signifikan $5 \%$ lebih besar rxy hitung dari rxy tabel yaitu: 10,059>0,176. Maka dapat disimpulkan bahwa semakin baik kontrol diri siswa semakin baik pula kemampuan menyesuaikan diri dan sebaliknya. Sehingga kontrol diri siswa berkolersi positif dengan penyesuaian diri siswa.

\section{KESIMPULAN DAN SARAN}

Setiap kegiatan penelitian yang dilakukan selalu ada tujuan yang ingin dicapai. Adapun tujuan yang ingin dicapai dalam penelitian ini adalah untuk mengetahui Hubungan Antara Kontrol Diri Dengan Penyesuian Diri Pada Siswa SMA Negeri 1 Taliwang Kabupaten Sumbawa Barat Tahun Pelajaran 2020/2021. Berdasarkan hasil perhitungan nilai $r_{x y}$ yang diperoleh dalam penelitian ini adalah 10,059, sedangkan nilai $r_{x y}$ dalam tabel dengan taraf signifikan 5\% dan $\mathrm{N}=1107$ adalah 0,176, kenyataan ini menunjukkan bahwa nilai $r_{y}$ yang diperoleh dalam penelitian ini adalah lebih besar dari pada nilai $r_{x y}$ tabel. Maka dapat dikemukakan bahwa hipotesis nol (Ho) ditolak dan hipotesis alternatif (Ha) diterima. Jadi kesimpulan analisis dalam penelitian ini adalah sebagai berikut: Ada Hubungan Antara Kontrol Diri Dengan Penyesuian Diri Pada Siswa SMA Negeri 1 Taliwang Kabupaten Sumbawa Barat Tahun Pelajaran 2020/2021.

Diharapkan kepada Kepala Sekolah agar memberikan pembinaan serta informasi kepada rekan-rekan guru, bahwa pelaksanaan Bimbingan dan Konseling sangat bermanfaat bagi siswa, terutama dalam membantu siswa. Diharapkan kepada guru Bimbingan dan Konseling agar profesional dalam menjalankan tugas, tetap memperkaya konsep-konsep ilmu pendidikan terutama ilmu Bimbingan dan Konseling. Lebih khususnya guru Bimbingan dan Konseling mampu dalam membantu siswa untuk membantu dalam Komunikasi Orang Tua dan Sikap Toleransi Siswa agar siswa mampu menyesuaikan diri secara positif dilingkungannya. Diharapkan untuk seluruh siswa untuk saling membantu terutama dalam menanamkan Komunikasi Orang Tua dan Sikap Toleransi Siswa agar siswa mampu 
berperilaku positif. Diharapkan kepada orang tua agar membantu, memberi motivasi, kasing sayang, mencintai sepenuh hati, mendidik anak secara demokratis agar nilai-nilai Komuikasi Orang Tua dan Sikap Toleransi dapat tertanam diri remaja. Bagi para peneliti, diharapkan hasil penelitian ini dapat dijadikan salah satu referensi, pedoman/acuan untuk mengadakan penelitian lebih lanjut.

\section{DAFTAR PUSTAKA}

Adelbert. 2014. Manusia Kebenaran. Jakara. Kanisius

Ali, M. \& Asrori, M., 2010. Psikologi Remaja: Perkembangan Peserta Didik. Cetakan Ke enam. Jakarta: PT. Bumi Aksara.

Aluh Hartati, Hariadi Ahmad dan Andika Rifzar Mandasingi. 2020. Hubungan antara Pengendalian Diri dengan Prestasi Siswa SMKN 1 Sumbawa Besar. Realita Jurnal Bimbingan dan Konseling Vol. 5 No 2 Edisi Oktober 2020. Hal 1051 - 1066. Prodi Bimbingan dan Konseling Fakultas Ilmu Pendidikan dan Psikologi Universitas Pendidikan Mandalika.

Alwisol. 2009. Psikologi Kepribadian edisi revisi. Malang : UMM Press.

Astrini, Ririn. R, \& Mujiburrahman. (2017). Efektivitas Bimbingan Belajar Untuk Meningkatkan Kemandirian Dalam Menyelesaikan TugasTugas Belajar Pada Siswa, 2 (2), 398 405.

Calhoun, J.P \& Acocella, J.R 1990. Psikologi tentang Penyesuian diri dan kecemasan, Terj. Satmiko S. R. Semarang: IKIP Pres.

Caplin, J.P. 2005. Kamus Lengkap Psikologi (Jakarta: PT. Raja Grafindo Persada.
Desmita. 2014. Psikologi Perkembangan Peserta Didik. Bandung: PT Rem aja Rosdakarya.

Fatimah, E. 2010.Psikologi Perkembanga $n$ Peserta Didik. Bandung: CV Pu staka Setia.

Goleman, Daniel. 2005. Kecerdasan Emosi: Untuk Mencapai Puncak Prestasi. Terjemahan Alex Tri Kantjono. PT. Gramedia Pustaka Utama. Jakarta.

Gottfredson, M. R. \& Hirschi, T. (1990). A General Theory of A Crime. Stanford: Stanford University Press.

Gunarsa \& Yulia. 2010. Psikologi Untuk Keluarga. Jakarta ; Penerbit Libri.

Hariadi Ahmad dan Aluh Hartati. 2016. Panduan Pelatihan Self Advocacy Siswa SMP untuk Konselor Sekolah. LPP Mandala. Mataram

Hariadi Ahmad dan Aluh Hartati. 2016. Penerapan Teknik Structure Learning Approach dalam Meningkatkan Self Advocacy Mahasiswa Prodi BK IKIP Mataram. Realita Jurnal Bimbingan dan Konseling Vol. 1 No 2 Edisi Oktober 2016. Hal 117 - 127. Prodi Bimbingan dan Konseling Fakultas Ilmu Pendidikan IKIP Mataram

Hariadi Ahmad dan Dini Kurnia. 2017. Pengaruh Teknik Biblio Edukasi Terhadap Rasa Rendah Diri Pada Siswa Kelas XI di SMA Negeri 8 Mataram. Realita Jurnal Bimbingan dan Konseling Vol. 2 No 1 Edisi April 2017. Hal 194 202. Prodi Bimbingan dan Konseling Fakultas Ilmu Pendidikan IKIP Mataram

Hariadi Ahmad, Ahmad Zainul Irfan dan Dedi Ahlufahmi. 2020. Hubungan antara Pola Asuh Orang Tua dengan Penyesuaian Diri Siswa. Realita Jurnal Bimbingan dan Konseling Vol. 5 No 1 Edisi April 
2020. Hal 950 - 966. Prodi Bimbingan dan Konseling Fakultas Ilmu Pendidikan dan Psikologi Universitas Pendidikan Mandalika.

Hariadi Ahmad, Aluh Hartati dan Jessica Festy Maharani. 2020. Pengaruh Dukungan Psikologis Awal pada Remaja dalam Pencegahan Covid 19. Realita Jurnal Bimbingan dan Konseling Vol. 5 No 2 Edisi Oktober 2020. Hal 1091 - 1106. Prodi Bimbingan dan Konseling Fakultas Ilmu Pendidikan dan Psikologi Universitas Pendidikan Mandalika.

Hariadi Ahmad, Aluh Hartati, dan Nuraeni. 2018. Penerapan Teknik Structure Learning Approach (SLA) dalam Meningkatkan Kesadaran Empati Diri Siswa Madrasah Aliyah Al Badriyah. Realita Jurnal Bimbingan dan Konseling Vol. 3 No 2 Edisi Oktober 2018. Hal $600-605$ Prodi Bimbingan dan Konseling Fakultas Ilmu Pendidikan IKIP Mataram.

Hariadi Ahmad, dan Lalu Andry Adifa Maulana. 2019. Pengaruh Teknik Video Edukasi Terhadap Berfikir Positif Siswa SMPN 16 Mataram. Realita Jurnal Bimbingan dan Konseling Vol. 4 No 1 Edisi April 2019. Hal 727 - 741. Prodi Bimbingan dan Konseling Fakultas Ilmu Pendidikan IKIP Mataram.

Hariadi Ahmad, dan Yolana Oktaviani. 2019. Pengaruh Teknik Self Instruction Terhadap Harga Diri Siswa Kelas Kelas XI di SMK Negeri 1 Lingsar Kabupaten Lombok Barat. Realita Jurnal Bimbingan dan Konseling Vol. 4 No 2 Edisi Oktober 2019. Hal 806 - 815. Prodi Bimbingan dan
Konseling Fakultas Ilmu Pendidikan IKIP Mataram.

Hariadi Ahmad, Lidya Wurru dan Jessica Festy Maharani. 2021. Hubungan antara Keharmonisan Keluarga dengan Perilaku Agresif pada Siswa Madrasah Aliyah Raudlatusshibyan NW Belencong. Realita Jurnal Bimbingan dan Konseling Vol. 6 No 1 Edisi April 2021. Hal 1205 - 1212. Prodi Bimbingan dan Konseling Fakultas Ilmu Pendidikan dan Psikologi Universitas Pendidikan Mandalika.

Hariadi Ahmad, Mustakim dan Syafaruddin. 2018. Hubungan antara Penyesuaian Diri dengan Berfikir Positif Siswa Kelas VIII SMP Negeri Seteluk Kabupaten Sumbawa Barat. Realita Jurnal Bimbingan dan Konseling Vol. 3 No 1 Edisi April 2018. Hal $482-$ 494. Prodi Bimbingan dan Konseling Fakultas Ilmu Pendidikan IKIP Mataram

Hasrul dan Hariadi Ahmad. 2021. Mereduksi Prasangka Etnik Siswa dengan Teknik Restructuing Cognitive Suatu Krangka Konseptual. Realita Jurnal Bimbingan dan Konseling Vol. 6 No 1 Edisi April 2021. Hal 1213 - 1222. Prodi Bimbingan dan Konseling Fakultas Ilmu Pendidikan dan Psikologi Universitas Pendidikan Mandalika.

Istiyono, W \& Silaban, O. 2006. Kamus Besar Bahasa Indonesia, Batam: Karisma Publishing Group.

Lin Novita. 2013. Hubungan Antara Kontrol Diri dengan Intensi POD Pada Anggota Kepolisin Reserse Kriminal. Skripsi. Universitas Diponegoro. 
Margono, S. 2010 Metodologi Penelitian Pendidikan . Jakarta : PT Rineka Cipta.

Mufidah. 2008. Psikologi Kekuarga Islam Berwawasan Gender, Malang: UIN Malang Press.

Panuju, P \& Umami, I. 1999. Psikologi Remaja. Yogyakarta: Tiara Remaja Yogya.

Risnawita \& Ghufron. 2012. Teori-Teori Psikologi. Jogjakarta: PT Ar-Ruzz Media.

Ryzkanevy Putri. 2009. Hubungn Antara Persepsi terhadap dukungan social orang tua dengan penyesuaian diri dalam penyusunan skripsi pada mahasiswa Fakultas Psikologi Universitas Diponegoro. Skripsi. Universitas Diponegoro

2013

Sobur, M.Si.

Psikologi Umum Dalam Lintasan

Sejarah. Bandung: CV Pustaka Setia.

Subana. 2005. Statistik Pendidikan. CV. Pustaka Setia: Bandung.
Sugiyono. 2016. Metode Penelitian Pendidikan (Pendekatan Kuantitatif, Kualitatif, dan $R$ \& $D)$. Bandung: Alfabeta.

Suharsimi, A. 2013. Prosedur Penelitian. Jakarta: PT Rineka Cipta.

Sukardi. 2012. Metode Penelitian Pendidikan Tindakan Kelas. Yogyakarta: Bumi Aksara.

Sunarto. 2008. Perkembangan Peserta Didik. Jakarta: PT Asdi Mahasatya.

Syahfa'at. 2015. Hubungan Kontrol Diri dengan Penyesuaian Diri Peserta Didik Kelas XI SMK 3 PGRI Kediri . Skripsi. Universitas Nusantara Kediri.

Tim IKIP Mataram 2011. Pedoman Pembimbingan Dan Penulisan Karya Ilmiah IKIP Mataram. Mataram: IKIP Mataram.

Tu'u. 2004. Peran Disiplin pada Perilaku dan Prestasi Belajar. Jakarta: Grasindo 


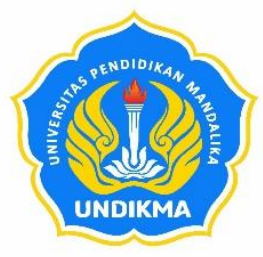

\section{UNIVERSITAS PENDIDIKAN MANDALIKA FAKULTAS ILMU PENDIDIKAN DAN PSIKOLOGI PROGRAM STUDI BIMBINGAN DAN KONSELING Jurnal Realita}

Gedung Dwitiya Lt.3. Jln Pemuda 59A Mataram-NTB 83125 Tlp (0370) 638991 e-mail: realita@undikma.ac.id; web: e-journal.undikma.ac.id

\section{PEDOMAN PENULISAN}

1. Naskah merupakan hasil penelitian, pengembangan atau kajian kepustakaan di bidang pendidikan, pengajaran, pembelajaran, bimbingan dan konseling, dan Psikologi

2. Naskah merupakan tulisan asli penulis dan belum pernah dipublikasikan sebelumnya dalam jurnal ilmiah lain,

3. Naskah dapat ditulis dalam Bahasa Indonesia atau Bahasa Inggris.

4. Penulisan naskah mengikuti ketentuan sebagai berikut:

$\begin{array}{llll}\text { Program } & \text { MS Word } & \text { Margin kiri } & 3.17 \mathrm{~cm} \\ \text { Font } & \text { Times New Roman } & \text { Margin kanan } & 3.17 \mathrm{~cm} \\ \text { Size } & 12 & \text { Margin atas } & 2.54 \mathrm{~cm} \\ \text { Spasi } & 1.0 & \text { Margin bawah } & 2.54 \mathrm{~cm} \\ \text { Ukuran kertas } & \text { A4 } & \text { Maksimum 20 halaman }\end{array}$

5. Naskah ditulis dengan sistematika sebagai berikut: Judul (huruf biasa dan dicetak tebal), nama-nama penulis (tanpa gelar akademis), instansi penulis (program studi, jurusan, universitas), email dan nomor telpon penulis, abstrak, kata kunci, pendahuluan (tanpa sub-judul), metode penelitian (tanpa sub-judul), hasil dan pembahasan, simpulan dan saran (tanpa sub-judul), dan daftar pustaka.

Judul secara ringkas dan jelas menggambarkan isi tulisan dan ditulis dalam huruf kapital. Keterangan tulisan berupa hasil penelitian dari sumber dana tertentu dapat dibuat dalam bentuk catatan kaki. Fotocopy halaman pengesahan laporan penelitian tersebut harus dilampirkan pada draf artikel.

Nama-nama penulis ditulis lengkap tanpa gelar akademis.

Alamat instansi penulis ditulis lengkap berupa nama sekolah atau program studi, nama jurusan dan nama perguruan tinggi. Penulis yang tidak berafiliasi pada sekolah atau perguruan tinggi dapat menyertakan alamat surat elektronik dan nomor telpon.

Abstrak ditulis dalam 2 (dua) bahasa: Bahasa Inggris dan Bahasa Indonesia. Naskah berbahasa Inggris didahului abstrak berbahasa Indonesia. Naskah berbahasa Indonesia didahului abstrak berbahasa Inggris. Panjang abstrak tidak lebih dari 200 kata. Jika diperlukan, tim redaksi dapat menyediakan bantuan penerjemahan abstrak kedalam bahasa Inggris.

Kata kunci (key words) dalam bahasa yang sesuai dengan bahasa yang dipergunakan dalam naskah tulisan dan berisi 3-5 kata yang benar-benar dipergunakan dalam naskah tulisan.

Daftar Pustaka ditulis dengan berpedoman pada Pedoman Penulisan Karya Ilmiah Universitas Pendidikan Mandalika. 


\begin{tabular}{|c|c|c|c|c|c|}
\hline & & & & \\
JURNAL & VOLUME & NOMOR & EDISI & HALAMAN & P ISSN : 2503 - 1708 \\
REALITA & 6 & 2 & Oktober 2021 & $1326-1430$ & E ISSN : 2722 - 7340 \\
& & & & \\
\hline
\end{tabular}

Alamat Qedaksi:

Program Studi Bimbingan dan Konseling Fakultas Ilmu Pendidikan dan Psikologi

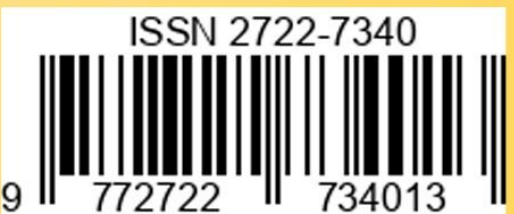

Universitas Pendidikan Mandalika

Gedung Dwitiya, Lt. 3 Jalan Pemuda No. 59A Mataram Telp. (0370) 638991

Email : realita@undikma.ac.id

Web : e-journal.undikma.ac.id

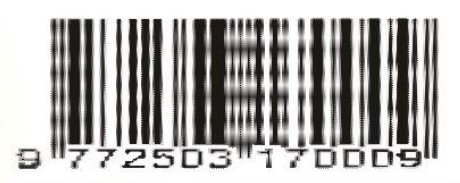

